\title{
Nitric Oxide Donors Enhance the Frequency Dependence of Dopamine Release in Nucleus Accumbens
}

\author{
Henrike Hartung*, 1,2,3, Sarah Threlfell ${ }^{1,2}$ and Stephanie J Cragg ${ }^{1,2}$ \\ 'Department of Physiology, Anatomy and Genetics, University of Oxford, Oxford, UK; '² Oxford Parkinson's Disease Centre, University of Oxford, \\ Oxford, UK; ${ }^{3}$ Department of Pharmacology, University of Oxford, Oxford, UK
}

\begin{abstract}
Dopamine (DA) neurotransmission in the nucleus accumbens (NAc) is critically involved in normal as well as maladaptive motivated behaviors including drug addiction. Whether the striatal neuromodulator nitric oxide (NO) influences DA release in NAc is unknown. We investigated whether exogenous $\mathrm{NO}$ modulates DA transmission in NAc core and how this interaction varies depending on the frequency of presynaptic activation. We detected DA with cyclic voltammetry at carbon-fiber microelectrodes in mouse NAc in slices following stimuli spanning a full range of DA neuron firing frequencies $(1-100 \mathrm{~Hz})$. NO donors 3-morpholinosydnonimine hydrochloride (SIN-I) or z-I-[N-(3-ammoniopropyl)-N-(n-propyl)amino]diazen-I-ium-I,2-diolate (PAPA/NONOate) enhanced DA release with increasing stimulus frequency. This NO-mediated enhancement of frequency sensitivity of DA release was not prevented by inhibition of soluble guanylyl cyclase (sGC), DA transporters, or large conductance $\mathrm{Ca}^{2+}$-activated $\mathrm{K}^{+}$channels, and did not require glutamatergic or GABAergic input. However, experiments to identify whether frequency-dependent $\mathrm{NO}$ effects were mediated via changes in powerful acetylcholine-DA interactions revealed multiple components to $\mathrm{NO}$ modulation of DA release. In the presence of a nicotinic receptor antagonist (dihydro- $\beta$-erythroidine), NO donors increased DA release in a frequency-independent manner. These data suggest that $\mathrm{NO}$ in the NAc can modulate DA release through multiple GC-independent neuronal mechanisms whose net outcome varies depending on the activity in DA neurons and accumbal cholinergic interneurons. In the presence of accumbal acetylcholine, NO promotes the sensitivity of DA release to presynaptic activation, but with reduced acetylcholine input, NO will promote DA release in an activityindependent manner through a direct action on dopaminergic terminals.

Neuropsychopharmacology (20 I I) 36, I8I I-1822; doi:I0.1038/npp.201 I.62; published online 20 April 201 I
\end{abstract}

Keywords: nitric oxide; acetylcholine; dopamine; striatal cholinergic interneurons; nucleus accumbens; voltammetry

\section{INTRODUCTION}

The nucleus accumbens (NAc), the major part of the limbic ventral striatum, has an important role in normal goaldirected or motivated behaviors as well as in maladaptive states, including drug addiction and schizophrenia. Here, inputs from major limbic-associated brain regions like the medial prefrontal cortex, basolateral amygdala, and ventral subiculum of the hippocampus converge (Finch, 1996; French and Totterdell, 2002, 2003; Groenewegen et al, 1987, 1999; Mulder et al, 1998; O'Donnell et al, 1999; Sesack and Grace, 2010; Wright and Groenewegen, 1995), are integrated with thalamic inputs (Berendse and Groenewegen, 1990; Smith et al, 2004), and interface with motor loops of the basal ganglia (Groenewegen and Trimble, 2007; Groenewegen et al, 1996; Mogenson et al, 1980; Sesack

\footnotetext{
*Correspondence: Dr H Hartung, Department of Pharmacology, University of Oxford, Mansfield Road, Oxford OXI 3QT, UK, Tel: + 44 (0)|865 27| 642, Fax: + 44 (0)|865 27| 853,

E-mail: henrike.hartung@pharm.ox.ac.uk

Received 5 December 2010; revised 15 March 201।; accepted 22 March 2011
}

and Grace, 2010; Zahm, 2000). These interactions are powerfully modulated by dopaminergic innervation from the ventral tegmental area (Ikemoto, 2007; Voorn et al, 1986). Dopaminergic neurons signal unpredicted rewards or other salient contextual stimuli and their conditioned cues by a shift in firing rates from tonic low frequencies to brief bursts at high frequency (Matsumoto and Hikosaka, 2009; Schultz, 1986, 2002), and corresponding accumbal DA release influences accumbal output and long-term plasticity (Morris et al, 2010; Reynolds and Wickens, 2002; Schultz, 2010).

How the release of DA reflects dynamic changes in activity in dopaminergic neurons is governed by the local regulation of release probability within the NAc (Cragg, 2003, 2006). For example, DA release is powerfully modulated by acetylcholine ( $\mathrm{ACh}$ ) arising from intrinsic cholinergic interneurons (ChIs) (Cragg, 2006; Exley et al, 2008; Rice and Cragg, 2004; Threlfell et al, 2010). Nitric oxide (NO) is another potent neuromodulator that is thought to be produced locally by neuronal nitric oxide synthase (uNOS) containing accumbal interneurons (French et al, 2005; Hidaka and Totterdell, 2001; Kraus and Prast, 2001), but how NO influences the dynamic signaling of activity by DA in NAc is currently unknown. 
Interactions between NO and DA have been extensively studied in the dorsal striatum, where NO modulates the excitability of striatal GABAergic projection neurons (West and Grace, 2004), corticostriatal synaptic plasticity (Calabresi et al, 1999a,b), and the release of various neurotransmitters including glutamate, GABA, ACh, serotonin, and DA (Prast et al, 1995, 1998; Prast and Philippu, 2001; Trabace and Kendrick, 2000; West and Galloway, 1996, 1997a, b, 1998). However, NO in the dorsal striatum is reported either to facilitate (Black et al, 1994; Buyukuysal, 1997; Iravani et al, 1998; Liang and Kaufman, 1998; Lonart et al, 1993; Stewart et al, 1996; Trabace and Kendrick, 2000; West and Galloway, 1996, 1997a, b, 1998; Zhu and Luo, 1992) or inhibit DA release (Guevara-Guzman et al, 1994; Segovia and Mora, 1998; Silva et al, 1995, 2003). The effector mechanisms have been suggested to include inhibition of DA transporters (DATs) (for a review see, Kiss and Vizi, 2001) as well as indirect mechanisms that involve NO activation of soluble guanylyl cyclase (sGC) in striatal projection neurons, which through their projections to the substantia nigra subsequently modify the activity of DA neurons (West and Grace, 2000) and NO-mediated increases in local glutamate levels (Bogdanov and Wurtman, 1997; Guevara-Guzman et al, 1994; Trabace and Kendrick, 2000; West and Galloway, 1997a, b), which might subsequently modify DA release (for a review see, David et al, 2005).

We used fast-scan cyclic voltammetry (FCV) at carbonfiber microelectrodes in striatal slices to identify how exogenous NO modulates endogenous DA release in NAc core during a range of evoked activity that spans the frequencies seen for dopaminergic neurons in vivo. We show that the outcome of NO on DA release in NAc varies depending on the activity in DA axons as well as in other accumbal neurons.

\section{MATERIALS AND METHODS}

\section{Brain Slice Preparation and Voltammetry}

Coronal striatal slices $(300 \mu \mathrm{m})$ containing the NAc were prepared from brains of $26-35 \mathrm{~g}$ CD-1 male mice (Harlan, Oxon, UK). The sections were cut on a Vibratome (Leica) in ice-cold oxygenated HEPES-buffered artificial cerebrospinal fluid (HEPES-aCSF) containing $\mathrm{NaCl}(120 \mathrm{mM}), \mathrm{NaHCO}_{3}$ (20 mM), D-glucose $(10 \mathrm{mM})$, HEPES acid $(6.7 \mathrm{mM})$, HEPES salt $(3.3 \mathrm{mM}), \mathrm{KCl}(5 \mathrm{mM}), \mathrm{CaCl}_{2}(2.4 \mathrm{mM}), \mathrm{KH}_{2} \mathrm{PO}_{4}$ $(1.25 \mathrm{mM})$, and $\mathrm{MgSO}_{4}(2 \mathrm{mM})$ saturated with $95 \% \mathrm{O}_{2} / 5 \%$ $\mathrm{CO}_{2}$. After maintaining slices for at least an hour in HEPESaCSF at room temperature, they were transferred to the recording chamber and allowed to equilibrate for another hour with the superfusion medium of the recording chamber, namely bicarbonate-buffered aCSF containing $\mathrm{NaCl}(125 \mathrm{mM}), \mathrm{NaHCO}_{3}(26 \mathrm{mM})$, D-glucose $(10 \mathrm{mM}), \mathrm{KCl}$ (3.8 mM), $\mathrm{CaCl}_{2}(2.4 \mathrm{mM}), \mathrm{KH}_{2} \mathrm{PO}_{4}(1.2 \mathrm{mM})$, and $\mathrm{MgSO}_{4}$ $(1.3 \mathrm{mM})$, and saturated with $95 \% \mathrm{O}_{2} / 5 \% \mathrm{CO}_{2}$. Recordings were carried out in aCSF at a flow rate of $1.3 \mathrm{ml} / \mathrm{min}$ and a bath temperature of $32-33^{\circ} \mathrm{C}$.

Extracellular DA concentration $\left([\mathrm{DA}]_{\mathrm{o}}\right)$ was monitored and quantified using FCV as described previously (Cragg, 2003; Rice and Cragg, 2004; Threlfell et al, 2010). Briefly, recordings were made with 7 - to $10 \mu \mathrm{m}$-diameter carbon-fiber microelectrodes of tip lengths $\sim 50-100 \mu \mathrm{m}$ that were fabricated in-house. The carbon-fiber electrode tip was inserted $100 \mu \mathrm{m}$ into the tissue in the NAc core, ventral to the anterior commissure, and voltammetry was performed using a Millar Voltammeter (PD Systems, Surrey, UK). The applied voltage was a triangular waveform, with a voltage range of -0.7 to $+1.3 \mathrm{~V}$ and back $v s$ an $\mathrm{Ag} / \mathrm{AgCl}$ reference electrode at a scan rate of $800 \mathrm{~V} / \mathrm{s}$ and a sampling frequency of $8 \mathrm{~Hz}$.

All evoked currents were recorded in the faradaic mode, showing currents after an electronic subtraction of background currents. These background-subtracted currents were monitored and recorded on a computer for analysis using Strathclyde Whole Cell Program (University of Strathclyde, Glasgow, Scotland). The evoked current profiles were attributed to DA by comparison of their potentials for peak oxidation and reduction currents with those of DA in calibration media $(500-600$ and $-200 \mathrm{mV} v \mathrm{~s}$ $\mathrm{Ag} / \mathrm{AgCl}$, respectively). Profiles of $[\mathrm{DA}]_{\mathrm{o}}$ vs time were obtained by sampling the current at the DA oxidation peak.

\section{Electrode Calibrations}

Electrode sensitivity to DA $(\mathrm{nA} / \mu \mathrm{M})$ in the presence of each added drug compound was determined from standard curves for DA oxidation current $v s$ applied DA concentration for a physiological range of DA concentrations $(1-3 \mu \mathrm{M})$ in aCSF in the presence of all experimental drugs, singly, and in combination as used experimentally. Some of the applied drugs decreased absolute electrode sensitivity to DA, for example, electrode sensitivity to DA was decreased in the presence of 3-morpholinosydnonimine hydrochloride (SIN-1) $(500 \mu \mathrm{M})$ by $\sim 63 \%$, in the presence of $z-1-[N-(3-$ ammoniopropyl)- $N$-( $n$-propyl)amino]diazen-1-ium-1,2-diolate (PAPA/NONOate) $(300 \mu \mathrm{M})$ by $\sim 74 \%$, and in the presence of $1 \mathrm{H}$-[1,2,4] oxadiazolo[4,3-a]quinoxalin-1-one (ODQ) $(100 \mu \mathrm{M})$ by $\sim 40 \%$. We used appropriately modified calibration factors determined from each and every drug condition to calibrate the electrodes. Note, we also confirmed that these effects of the parent compound on DA sensitivity occurred when electrodes were situated in the tissue environment by performing additional calibrations in tissue (data not illustrated; required higher applied DA concentrations and inclusion of a DA uptake inhibitor (cocaine) to allow applied DA in the striatum to reach levels approaching low micromolar). Importantly, the relationship between $[\mathrm{DA}]_{\mathrm{o}}$ and oxidation current remained linear in all drugs used for the range of $[\mathrm{DA}]_{\mathrm{o}}$ seen in situ (data not illustrated).

\section{Local Electrical Stimulation}

Local stimulations used to evoke DA release were applied by a surface, bipolar concentric electrode $(25 \mu \mathrm{m}$ diameter $\mathrm{Pt} / \mathrm{Ir}$; FHC, Bowdoinham, ME). Under a binocular microscope, the stimulating electrode was positioned flush with the tissue at a distance of $\sim 100 \mu \mathrm{m}$ from the recording electrode. Stimulus pulses of $200 \mu$ s duration were generated out-of-phase with FCV scans to prevent interference with the voltammetric current and applied at peri-maximal currents $(0.5-0.7 \mathrm{~mA})$. Release evoked with stimulation used here (either a single pulse or brief $4-5$ pulse trains) is 
inhibited by tetrodotoxin and is calcium-dependent (Cragg, 2003), but not modulated by ionotropic glutamate or GABA receptor activation (Cragg, 2003; Exley et al, 2008; Threlfell et al, 2010). However, DA release is controlled by ACh acting at presynaptic nicotinic ACh receptors on DA axons (Exley et al, 2008; Rice and Cragg, 2004; Zhang and Sulzer, 2004; Zhou et al, 2001). This local cholinergic input results from the activity of ChIs, which have been shown to be tonically active in slices as they are in vivo (Aosaki et al, 1994; Bennett and Wilson, 1999). ACh evoked by local electrical stimulation does not seem to add to already tonic levels generated by high tonic activity of ACh interneurons. DA release evoked by remote pathway stimulations was shown to be regulated by striatal ACh similarly to release evoked by local stimulations (Exley et al, 2008; Rice and Cragg, 2004).

\section{Experimental Design and Analysis}

Stimulus protocols were repeated at a minimum of 2-min intervals, which ensured stable, consistent release. To test the effect of frequency on DA release, a range of stimulations consisting of either a single pulse (1p) or four pulses (4p) at a range of frequencies spanning $5-100 \mathrm{~Hz}$ were applied in a randomized order in triplicate at each given recording site. These stimulus frequencies include the full range of physiological DA neuron firing rates reported in vivo, consisting of tonic firing rates $(<10 \mathrm{~Hz})$ and phasic bursts (firing rates approx. $15-25 \mathrm{~Hz}$ or higher) that accompany salient events (Bayer and Glimcher, 2005; Hyland et al, 2002; Schultz, 1986; Morris et al, 2004), and also higher frequencies as used previously that are particularly useful for probing for changes in release probability. We have established that the peak value of $[D A]_{0}$ for $1 \mathrm{~Hz}$ is indistinguishable from $1 \mathrm{p}$ (data not illustrated), and for simplicity, we have used $1 \mathrm{p}$ data to represent $1 \mathrm{~Hz}$ outcome. Single-pulse stimulations were distributed regularly in time across each experiment (one $1 \mathrm{p}$ stimulation after three consecutive pulse train stimulations), to provide a reference value of $[D A]_{o}$ against which $[D A]_{o}$ evoked by other stimuli could be compared.

All data are means \pm standard error of the mean (SEM) and the sample size, $n$ is the number of observations. The number of animals in each data set is $\geqslant 3$. Data are expressed as $[\mathrm{DA}]_{\mathrm{o}}$ normalized to release by a single pulse in control conditions. Mean value of mean peak $[D A]_{0}$ for a single pulse across experiments were $0.67 \pm 0.06 \mu \mathrm{M}$ (range $0.39-1.7 \mu \mathrm{M})$. Comparisons for differences in means were assessed by two-way ANOVAs and post hoc Bonferroni multiple comparison $t$-tests using GraphPad Prism.

\section{Drug Application}

NO donors of two different classes were used: SIN-1, purchased from Tocris Bioscience (Bristol, UK), and PAPA/ NONOate, purchased from Alexis Biochemical (Nottingham, UK). SIN-1 was prepared fresh immediately before use in aCSF and protected from light. SIN-1 spontaneously generates NO in aqueous solution by decomposition (Feelisch and Noack, 1987) at rates expected to be in the low micromolar range per minute for $500 \mu \mathrm{M}$ SIN-1 as inferred by Feelisch et al (1989) and Hogg et al (1992).
PAPA/NONOate was dissolved in $0.01 \mathrm{M} \mathrm{NaOH}$ to a stock concentration of $60 \mathrm{mM}$ and diluted in aCSF before use to the desired final concentration. A concentration of $300 \mu \mathrm{M}$ PAPA/NONOate as used in this study is expected to generate NO bath concentrations in the low micromolar range as inferred by Garthwaite et al (2002). Resulting tissue NO concentrations are likely to be several orders of magnitude lower than bath concentrations (eg, Garthwaite et al, 2002) owing to significant consumption of NO by tissue (Hall and Garthwaite, 2006).

D-AP5, bicuculline, dihydro- $\beta$-erythroidine $(\mathrm{DH} \beta \mathrm{E})$, GYKI-52466 hydrochloride, iberiotoxin (IbTx), (S)-MCPG, $\mathrm{ODQ}$, and saclofen were purchased from Tocris Bioscience or Ascent Scientific (Bristol, UK). Trolox was purchased from Merck (Hull, UK) and nomifensine was purchased from Sigma Aldrich (Cambridge, UK). The drugs were dissolved in water, aqueous acid (GYKI-52466 hydrochloride, nomifensine), aqueous alkali ((S)-MCPG, saclofen), aqueous DMSO (ODQ), or ethanol (Trolox), and were either prepared fresh or stored as stock aliquots of $500-2500 \times$ final concentrations at $-20^{\circ} \mathrm{C}$ until required. Stock aliquots were diluted with oxygenated aCSF to final concentrations immediately before use.

Each drug condition involved drug application for approximately $60 \mathrm{~min}$ to include wash-on and a complete set of stimulations (40-45 min). Drug effects could be observed already 3-7 min after drug application and were maximal after $15 \mathrm{~min}$. Thereafter, drug effects remained constant for the whole course of frequency testing.

\section{RESULTS}

\section{NO Donors Increase Evoked DA Release in a Frequency-Dependent Manner}

We explored how NO modulates DA release evoked by a range of different frequencies $(1-100 \mathrm{~Hz}, 4 \mathrm{p})$, which are in the range of firing rates that DA neurons display in vivo, but also include higher frequencies as used previously that are particularly useful for probing of changes in release probability. Dopaminergic neurons respond to salient stimuli by shifting from tonic (approx. $0.5-10 \mathrm{~Hz}$ ) frequencies to short phasic bursts of high-frequency firing (approx. $15-25 \mathrm{~Hz}$ or higher, durations $<200 \mathrm{~ms}$ ) (Hyland et al, 2002; Schultz, 1986).

In control conditions, evoked $[\mathrm{DA}]_{\mathrm{o}}$ varied slightly but significantly with stimulus frequency in mouse NAc core (Figure 1) by up to $172 \pm 6 \%$ of release by a single pulse, according to an inverted $\mathrm{U}$ relationship, as described previously (Exley et al, 2008). Application of the NO donor SIN-1 $(500 \mu \mathrm{M})$ significantly increased the dependence of evoked $[D A]_{o}$ on stimulus frequency (Figure $1 \mathrm{a}$ and $\mathrm{b}$; twoway ANOVA, frequency: $\mathrm{F}_{4,133}=72.55, P<0.001$; treatment: $\mathrm{F}_{2,133}=34.49 P<0.001$; interaction: $\mathrm{F}_{8,133}=10.19$, $P<0.001)$. Release by lower frequencies $(\leqslant 10 \mathrm{~Hz})$ remained unchanged, but release by higher frequencies $(\geqslant 25 \mathrm{~Hz})$ was significantly increased compared with control. Maximum $[\mathrm{DA}]_{\mathrm{o}}$ were evoked by $100 \mathrm{~Hz}(4 \mathrm{p} ; \sim 300 \%$ of release by a single pulse). Drug effects were reversible upon washout (Supplementary Figure S1a) and were concentration-dependent (data not illustrated). 
a

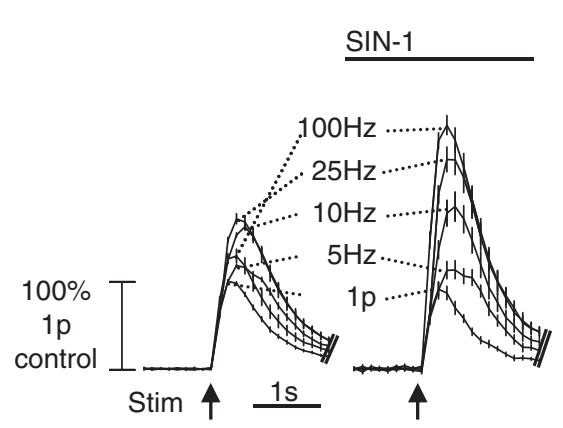

C

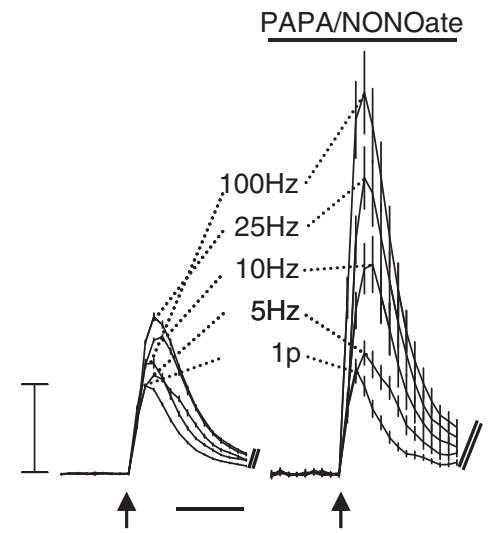

e
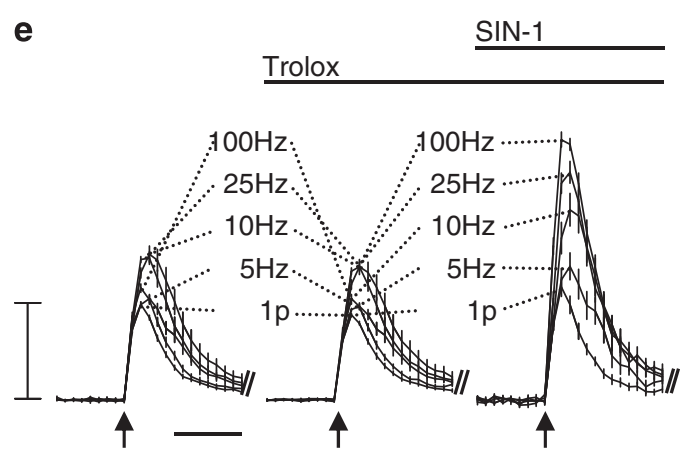

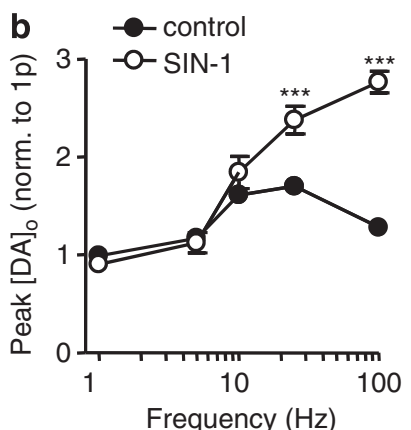

d
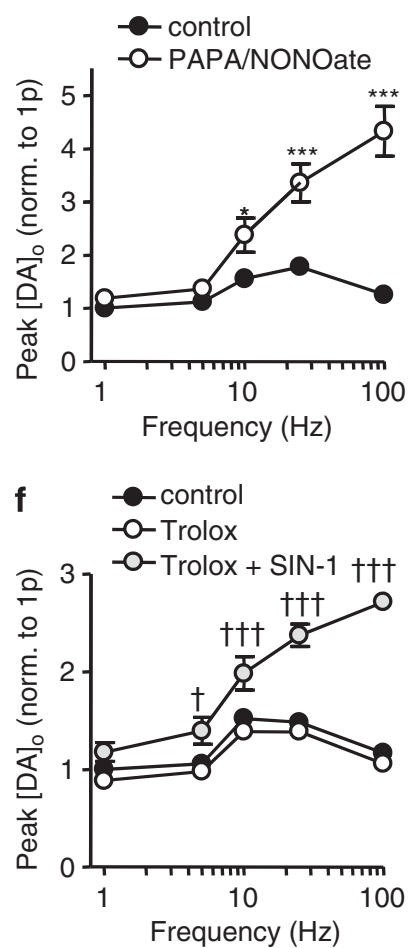

Figure I Nitric oxide (NO) donors increase evoked dopamine (DA) release in a frequency-dependent manner. (a, c, e) Profiles of mean extracellular DA concentration ([DA] $]_{0} \pm$ standard error of mean (SEM) vs time following stimuli (arrows) of either a single pulse ( $p$ ) or $4 p(5-100 \mathrm{~Hz})$ in (a) control conditions (left) and $\mathrm{NO}$ donor 3-morpholinosydnonimine hydrochloride (SIN-I) (500 $\mu \mathrm{M})$ (right), (c) control conditions (left) and NO donor z-I-[N-(3-ammoniopropyl)-N-(n-propyl)amino]diazen-I-ium-I,2-diolate (PAPA/NONOate) (300 $\mu$ M) (right) or (e) control conditions (left), Trolox $(200 \mu \mathrm{M})$ (center), and Trolox $+\mathrm{SIN}-\mathrm{I}$ (right). Data are normalized to peak [DA]。 evoked by Ip in controls. (b, d, f) Mean peak [DA]。 \pm SEM vs frequency at Ip or $4 p(5-100 \mathrm{~Hz})$ in (b) control conditions (filled circles) and NO donor SIN-I (unfilled) ( $n=9-15)$, (d) control conditions (filled circles) and NO donor PAPA/NONOate (unfilled), ( $n=9-17)$, or (f) control conditions (filled circles), Trolox (unfilled), and Trolox + SIN-I (gray fill) $(n=9-14)$. Data are normalized to peak [DA] evoked by Ip in controls. Asterisks indicate significance level in post hoc Bonferroni $t$-test for drug treatment vs controls, $* P<0.05$, ${ }^{*} * * P<0.00 \mathrm{I}$. Crucifixes indicate significance level in Bonferroni post hoc $t$-tests for Trolox vs Trolox $+S \mathrm{SIN}-\mathrm{I}$, ${ }^{\dagger} P<0.05$, $\dagger P<0.001$.

The effects of an alternative NO donor, PAPA/NONOate, was also explored. PAPA/NONOate $(300 \mu \mathrm{M})$, like SIN-1, significantly increased $[\mathrm{DA}]_{\mathrm{o}}$ in an activity-dependent manner (Figure $1 \mathrm{c}$ and d; two-way ANOVA, frequency: $\mathrm{F}_{4,92}=29.59, P<0.001$; treatment: $\mathrm{F}_{1,92}=89.09, P<0.001$; interaction: $\left.\mathrm{F}_{4,92}=18.25, P<0.001\right)$, which was reversible upon washout (Supplementary Figure S1b). Release evoked by lower frequencies $(\leqslant 5 \mathrm{~Hz})$ remained unchanged, but release by higher frequencies $(\geqslant 10 \mathrm{~Hz})$ was significantly increased compared with control. Greatest $[\mathrm{DA}]_{\mathrm{o}}$ were evoked by $100 \mathrm{~Hz}$ bursts (4p; 364\% of release by a single pulse). The similar effects observed with two different NO donors suggest that these effects were due to NO rather than any nonspecific effects of each donor or their different breakdown products. Thus, in subsequent experiments, NO action was explored using a single example donor only, SIN-1.

To confirm that the effect of SIN-1 were not due to the concurrent release of superoxide anions, the subsequent formation of peroxynitrite and consequent modification of striatal DA release (Trabace and Kendrick, 2000), we identified whether the effects of SIN-1 were prevented by 
the peroxynitrite scavenger Trolox (Edwards and Rickard, 2005; Halliwell et al, 1999; Regoli and Winston, 1999). Trolox alone $(200 \mu \mathrm{M})$ did not significantly modify evoked $[D A]_{o}$ compared with control conditions (Figure le and f). Furthermore, Trolox $(200 \mu \mathrm{M})$ did not prevent the subsequent effects of SIN-1 on increasing the activity dependence of evoked $[\mathrm{DA}]_{\mathrm{o}}$ (Figure $1 \mathrm{e}$ and $\mathrm{f}$; two-way ANOVA, frequency: $\mathrm{F}_{4,134}=50.72, \quad P<0.001$; treatment: $\mathrm{F}_{2,134}=$ $141.9 P<0.001$; interaction: $\left.\mathrm{F}_{8,134}=15.74, P<0.001\right)$. These data suggest that peroxynitrite did not contribute to the effect of SIN-1 on evoked $[D A]_{0}$.

\section{NO Donors Regulate DA Transmission via Guanylyl Cyclase-independent Mechanism}

NO is reported to act through a variety of effector mechanisms. One major target of NO is sGC (Bellamy et al, 2002; Garthwaite and Boulton, 1995). NO activation of sGC generates cyclic guanosine monophosphate (cGMP), which has a variety of downstream targets, for example, ion channels, phosphodiesterases, and protein kinases (Garthwaite and Boulton, 1995). However, the involvement of sGC in reported facilitatory effects of NO on DA levels in the striatum remains controversial. This facilitatory effect of NO on DA levels has been shown to be both sGC-dependent (Guevara-Guzman et al, 1994; Trabace and Kendrick, 2000) and sGC-independent (Buyukuysal, 1997; Rocchitta et al, 2004; Stewart et al, 1996; West and Galloway, 1996). We explored whether the effect of NO donors on the frequencydependent control of DA release identified here in NAc was sGC-dependent or -independent.

The sGC inhibitor ODQ $(100 \mu \mathrm{M})$ alone did not significantly change evoked $[D A]_{o}$ (Figure $\left.2 a-c\right)$, and furthermore, ODQ did not prevent the subsequent effects of SIN-1 (Figure 2a-c). SIN-1 significantly increased evoked $[D A]_{o}$ in a frequency-dependent manner (two-way ANOVA, frequency: $\mathrm{F}_{4,130}=44.09, P<0.001$; treatment: $\mathrm{F}_{2,130}=42.98$, $P<0.001$; interaction: $\left.\mathrm{F}_{8,130}=7.71, P<0.001\right)$, which was not different from the effect of SIN-1 alone (two-way ANOVA, treatment: $\mathrm{F}_{1,84}=2.22, \quad P>0.05$; interaction: $\mathrm{F}_{4,84}=1.32$, $P>0.05)$. These data suggest that NO-mediated effects on $[D A]_{o}$ observed here were sGC-independent.

Another frequently reported action of NO is S-nitrosylation of proteins such as ion channels. A commonly used approach to explore whether this mechanism underlies actions of NO is to block S-nitrosylation with N-ethylmaleimide (NEM). However, in pilot studies, NEM (2 mM) induced stimulus-independent continuous release of DA that prevented subsequent evoked DA release (data not illustrated), presumably via disruption of the SNARE complex. Thus, NEM is unsuitable as a tool to explore the role of S-nitrosylation in these experiments.

\section{Effect of NO on Evoked DA Release is not Mediated by Modulation of DA Reuptake}

Previous studies have reported that NO-mediated enhancement of extracellular DA levels occurs by inhibiting DA reuptake via blockade of the DAT in vitro (Buyukuysal, 1997; Lonart and Johnson, 1994; Pogun et al, 1994) and in vivo (Kiss et al, 1999; Lin et al, 1995). Our data have sufficiently high temporal resolution to enable changes in re-uptake rates to be indicated by changes in the time course of disappearance of the evoked extracellular DA signal. We compared the falling phases of the DA transients evoked by $100 \mathrm{~Hz}$ pulse trains in control conditions $v s$ those obtained during application of SIN-1. However, SIN-1 did not modify the decay of the DA signal (Figure 2d; contrast with Figure 2e, the change in decay of the DA signal seen after re-uptake blockade). Comparisons of the time required for peak evoked $[\mathrm{DA}]_{\mathrm{o}}$ to decay by $50 \%\left(t_{50}\right)$ following $100 \mathrm{~Hz}$ pulse trains in control $v s$ during application of SIN-1 did not reveal significant differences (control: $t_{50}=0.61 \pm$ $0.03 \mathrm{~s} ; \quad$ SIN-1: $t_{50}=0.62 \pm 0.03 \mathrm{~s}$, paired $t$-test, $P>0.05$, $n=9$ ). Furthermore, to ensure that modulation of the function of the DAT was not responsible for the SIN-1induced changes in the activity dependence of evoked $[D A]_{o}$, we explored the effect of SIN-1 in the presence of DAT inhibition. Application of the DAT inhibitor nomifensine alone $(10 \mu \mathrm{M})$ enhanced peak evoked $[\mathrm{DA}]_{\mathrm{o}}$ and significantly prolonged the extracellular lifetime of $[\mathrm{DA}]_{\mathrm{o}}$ (Figure $2 \mathrm{f}$ and g) as shown previously (Jones et al, 1995a, b, 1996; Schmitz et al, 2002). Subsequent application of SIN-1 significantly modified $[\mathrm{DA}]_{\mathrm{o}}$ in an activity-dependent manner (Figure $2 \mathrm{f}-\mathrm{h}$; two-way ANOVA, frequency: $\mathrm{F}_{4,181}=$ 16.50, $P<0.001$; treatment: $F_{2,181}=140.5 P<0.001$; interaction: $\mathrm{F}_{8,181}=5.75, P<0.001$ ) not different to the effect of SIN-1 alone (see Figure $2 \mathrm{~h}$ ), suggesting that modulation of DA re-uptake is not responsible for these NO-mediated effects on $[D A]_{0}$.

\section{Major Component of Effect of NO on DA Release is BK Channel-Independent}

One candidate sGC-independent mechanism through which NO has been reported to influence cellular excitability is via modulation of large conductance $\mathrm{Ca}^{2+}$-activated $\mathrm{K}^{+}$ (BK) channels. The BK current has been shown to be directly modulated by NO through S-nitrosylation of cysteine residues (and indirectly by activation of sGC depending on local NO concentrations) (Ahern et al, 2002). We explored whether BK channels might mediate NO effects on DA transmission. Blockade of BK channels with $\mathrm{IbTx}$ $(100 \mathrm{nM})$ significantly increased the inverted U-dependence of the relationship between evoked $[\mathrm{DA}]_{\mathrm{o}}$ and frequency. IbTx significantly increased [DA $]_{\mathrm{o}}$ evoked by 10 and $25 \mathrm{~Hz}$ compared with control (Figure 2i and j; two-way ANOVA, post hoc Bonferroni $t$-tests, $10 \mathrm{~Hz}: P<0.05, n=9$; $25 \mathrm{~Hz}$ : $P<0.01, n=9)$. The presence of IbTx, however, did not prevent SIN-1 effects. SIN-1 $(500 \mu \mathrm{M})$ significantly increased evoked $[\mathrm{DA}]_{\mathrm{o}}$ in an activity-dependent manner, with greatest effect at highest frequencies (Figure 2i-k; twoway ANOVA, frequency: $\mathrm{F}_{4,119}=208.1, P<0.001$; treatment: $F_{2,119}=312.0, P<0.001$; interaction: $F_{8,119}=22.29$, $P<0.001)$. IbTx did, however, slightly change the effect of SIN-1. In the presence of IbTx, SIN-1 appeared to more generally increase evoked $[\mathrm{DA}]_{\mathrm{o}}$ throughout the range of stimulation frequencies applied compared with the effects of SIN-1 in the absence of IbTx (Figure 2k; compare solid $v s$ dotted line). This apparent shift in the actions of SIN-1 may be due to a small component of NO action being via, or being shunted due to, a change in BK channel function. Nonetheless, a major activity-dependent component of $\mathrm{NO}$ action was independent of BK channels. 

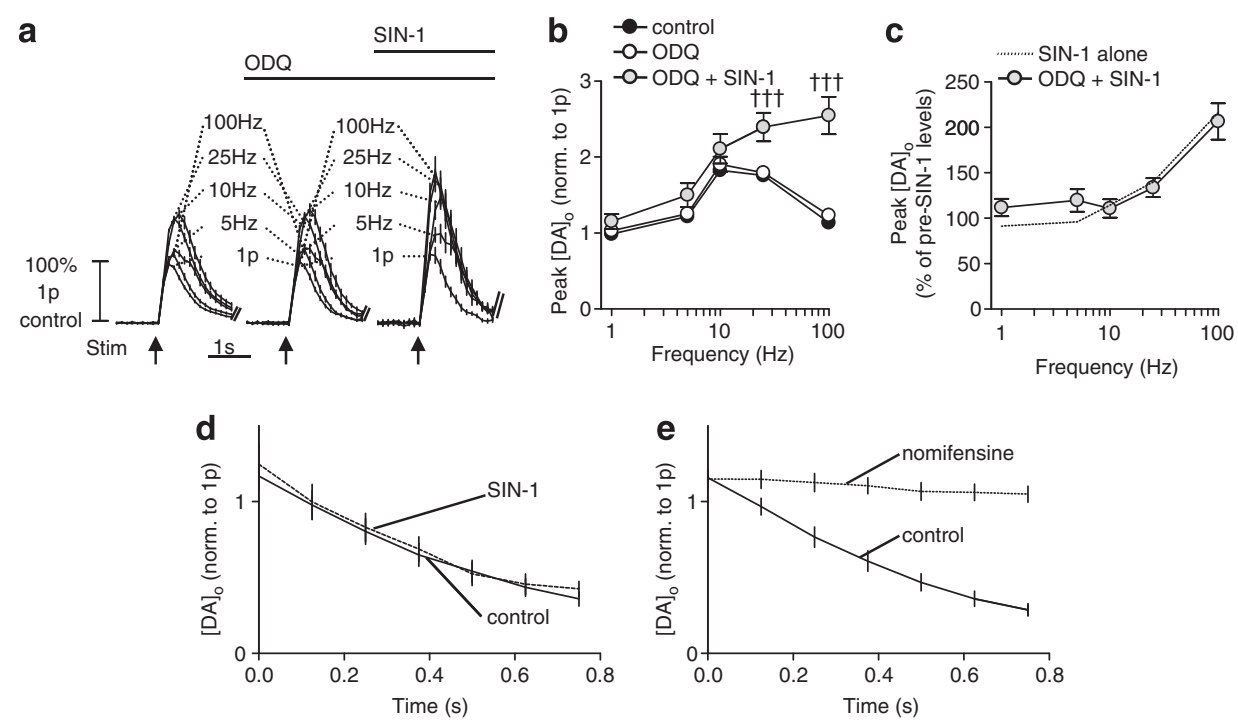

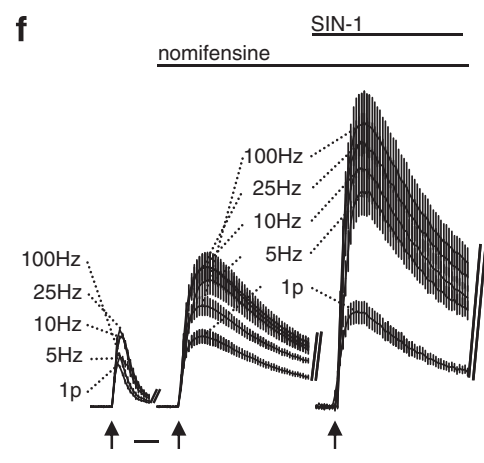

g
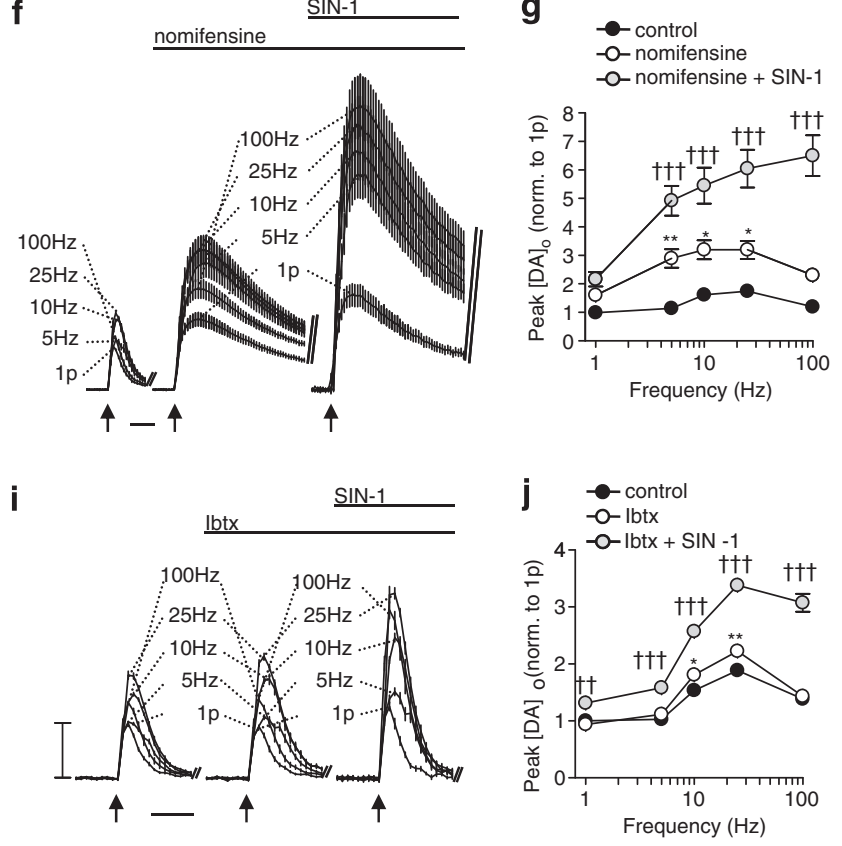

h

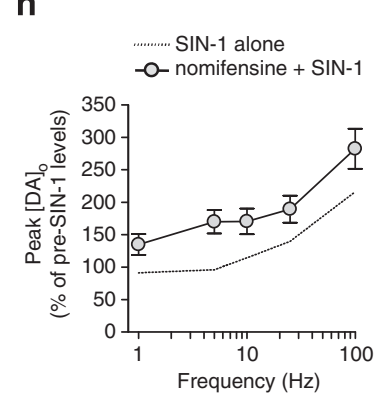

k

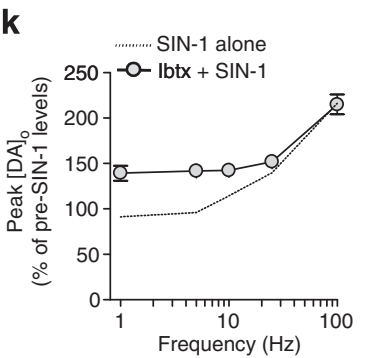

Figure 2 The effect of nitric oxide (NO) on evoked dopamine (DA) release is independent of soluble guanylyl cyclase (sGC) or DA re-uptake modulation and only a small component is dependent on $\mathrm{Ca}^{2+}$-activated $\mathrm{K}^{+}$(BK) channels. (a, $\mathrm{f}$, i) Profiles of mean extracellular DA concentration $\left([D A]_{0}\right) \pm$ standard error of mean (SEM) vs time following stimuli (arrows) of either I or $4 p(5-100 \mathrm{~Hz})$ in control conditions (left), various antagonists (center) (a, IH-[I,2,4]oxadiazolo[4,3-a]quinoxalin-I-one (ODQ), $100 \mu \mathrm{M}$; f, nomifensine, $10 \mu \mathrm{M}$; i, iberiotoxin (IbTx), $100 \mathrm{nM}$ ), and antagonist + 3morpholinosydnonimine hydrochloride $(\mathrm{SIN}-\mathrm{I})(500 \mu \mathrm{M})$ (right) normalized to peak [DA]。 evoked by I p in controls. $(\mathrm{b}, \mathrm{g}$, j) Mean peak [DA]。 \pm SEM vs frequency during Ip or $4 \mathrm{p}(5-100 \mathrm{~Hz})$ in control conditions (filled circles), antagonist (unfilled) (b, ODQ $(n=8-15)$; g, nomifensine $(n=\mid 2-20)$; j, IbTx $(n=9)$ ), and antagonist + SIN -I (gray fill) normalized to peak [DA]。 evoked by I in controls. Asterisks indicate significance level in post hoc Bonferroni t-test vs controls, $* P<0.05, * * P<0.01$. Crucifixes indicate significance level in Bonferroni post hoc $t$-tests for antagonist vs antagonist $+S I N-I, "{ }^{\dagger} P<0.01$, ${ }_{T \rightarrow} P<0.00 I$. (c, h, k) Mean peak [DA]。 vs frequency expressed as \% of peak [DA]。 evoked at that frequency before SIN-I cocktail application, to compare the effect of SIN-I on [DA]。 at each applied frequency in the presence of (c) ODQ, (h) nomifensine, or (k) IbTX vs SIN-I alone (dashed line; determined from data in Figure Ib). Error bars are also percentage of pre-SIN-I levels. (k) Although IbTx does not prevent the activity-dependent increase in DA release (two-way ANOVA, $P<0.001, n=9$ ), which is still prominent at $100 \mathrm{~Hz}$, the effects of $\mathrm{SIN}-1$ may be slightly modified towards a general frequencyindependent increase in DA release. (d, e) Falling phases of mean $[D A]_{0} \pm S E M$ profiles vs time released by high-frequency bursts $(4 \mathrm{p} / / \mathrm{l} 00 \mathrm{~Hz})$ in control (straight line) and (d) SIN-I or (e) nomifensine (dashed line) normalized to peak [DA]。 evoked by Ip in controls.

\section{NO Modulation of DA Release is Multifactorial}

We explored whether the effects of NO on DA release reported here are mediated directly by an action on DA axons, or indirectly via regulation of an intermediary neurotransmitter(s). Accumbal glutamate and GABA do not normally have significant roles in regulating DA release probability during discrete subsecond stimuli (Cragg, 2003; Exley et al, 2008; Threlfell et al, 2010). However, as GABAergic and glutamatergic transmission can be 
modulated by $\mathrm{NO}$ in vivo (Bogdanov and Wurtman, 1997; Guevara-Guzman et al, 1994; Trabace and Kendrick, 2000; West and Galloway, 1997a), we investigated whether a potential change of the local glutamatergic or GABAergic tone by NO contributed to the SIN-1 effect on DA release. Application of a cocktail of antagonists for glutamate (NMDA: D-AP5, $50 \mu \mathrm{M}$; AMPA: GYKI-52466, $10 \mu \mathrm{M}$; mGluR: $(S)-\mathrm{MCPG}, 200 \mu \mathrm{M})$ and GABA receptors $\left(\mathrm{GABA}_{\mathrm{A}}\right.$ : bicuculline, $10 \mu \mathrm{M}$; $\mathrm{GABA}_{\mathrm{B}}$ : saclofen, $50 \mu \mathrm{M}$ ) did not significantly modulate evoked $[\mathrm{DA}]_{\mathrm{o}}$ at any frequency applied compared with control (Figure $3 \mathrm{a}-\mathrm{c}$ ) as shown previously (Cragg, 2003; Exley et al, 2008; Threlfell et al, 2010). Furthermore, glutamate and GABA receptor blockade did not prevent the activity-dependent effect of subsequent SIN-1 application (Figure 3a-c; two-way ANOVA, frequency: $\mathrm{F}_{4,136}=35.22, P<0.001$; treatment: $\mathrm{F}_{2,136}=68.30, P<0.001$; interaction: $\mathrm{F}_{8,136}=9.72, P<0.001$ ), suggesting that the effect of NO on $[\mathrm{DA}]_{\mathrm{o}}$ is not via modulation of local glutamatergic or GABAergic tone.

Accumbal nicotinic ACh receptors (nAChRs) on dopaminergic terminals have a powerful control over DA release in the NAc (Exley et al, 2008; Rice and Cragg, 2004). Normally, endogenous accumbal ACh, released by tonically active ChIs, maintains ACh tone at accumbal nAChRs located on DA axons. This ACh tone ensures that initial DA release probability by a single stimulus pulse is high (Rice and Cragg, 2004; Zhou et al, 2001), that short-term depression of DA re-release at subsequent stimuli is prominent, and that sensitivity of DA release to frequency of activation is consequently limited (Cragg, 2003; Rice and
Cragg, 2004). Changes in nAChR activation in turn modify the frequency sensitivity of DA transmission. We explored whether NO effects on DA transmission were mediated wholly or in part via an action involving ChIs/ACh. Application of the nicotinic receptor antagonist, $\mathrm{DH} \beta \mathrm{E}$ $(1 \mu \mathrm{M})$, to block cholinergic input significantly modified evoked DA release in an activity-dependent manner (Figure $3 \mathrm{~d}$ and e; two-way ANOVA, frequency: $\mathrm{F}_{4,134}=463.9$, $P<0.001$; treatment: $F_{2,134}=602.4, P<0.001$; interaction: $\left.\mathrm{F}_{8,134}=127.1, \quad P<0.001\right)$, by reducing release by lower frequencies and enhancing release by higher frequencies as shown previously (Exley et al, 2008; Rice and Cragg, 2004). In the presence of $\mathrm{DH} \beta \mathrm{E}$, subsequent application of SIN-1 $(500 \mu \mathrm{M})$ only slightly modified further the activity dependence of evoked [DA] $]_{\mathrm{o}}$ (Figure 3f; two-way ANOVA, frequency: $\mathrm{F}_{4,134}=463.9, P<0.001$; treatment: $\mathrm{F}_{2,134}=602.4$, $P<0.001$; interaction: $\left.\mathrm{F}_{8,134}=127.1, P<0.001\right)$, but moreover, resulted in a significant increase $(63-89 \%)$ in $[D A]_{o}$ evoked by all frequencies compared with $\mathrm{DH} \beta \mathrm{E}$ alone (Figure $3 \mathrm{f}$; twoway ANOVA, frequency: $\mathrm{F}_{4,134}=463.9, P<0.001$; treatment: $\mathrm{F}_{2,134}=602.4, P<0.001$; interaction: $\left.\mathrm{F}_{8,134}=127.1, P<0.001\right)$.

These data suggest a combination of both direct and indirect effects of $\mathrm{NO}$ on DA release. In the absence of cholinergic input to DA terminals (ie, in the presence of $\mathrm{nAChR}$ antagonist $\mathrm{DH} \beta \mathrm{E}$ ), NO seems to act directly at the level of DA terminals to enhance release in a manner independent of stimulation frequency. However, in the presence of cholinergic input (ie, in the absence of $\mathrm{nAChR}$ antagonist $\mathrm{DH} \beta \mathrm{E}$ ), these direct effects of $\mathrm{NO}$ at the level of the DA terminal to increase release at all frequencies appear
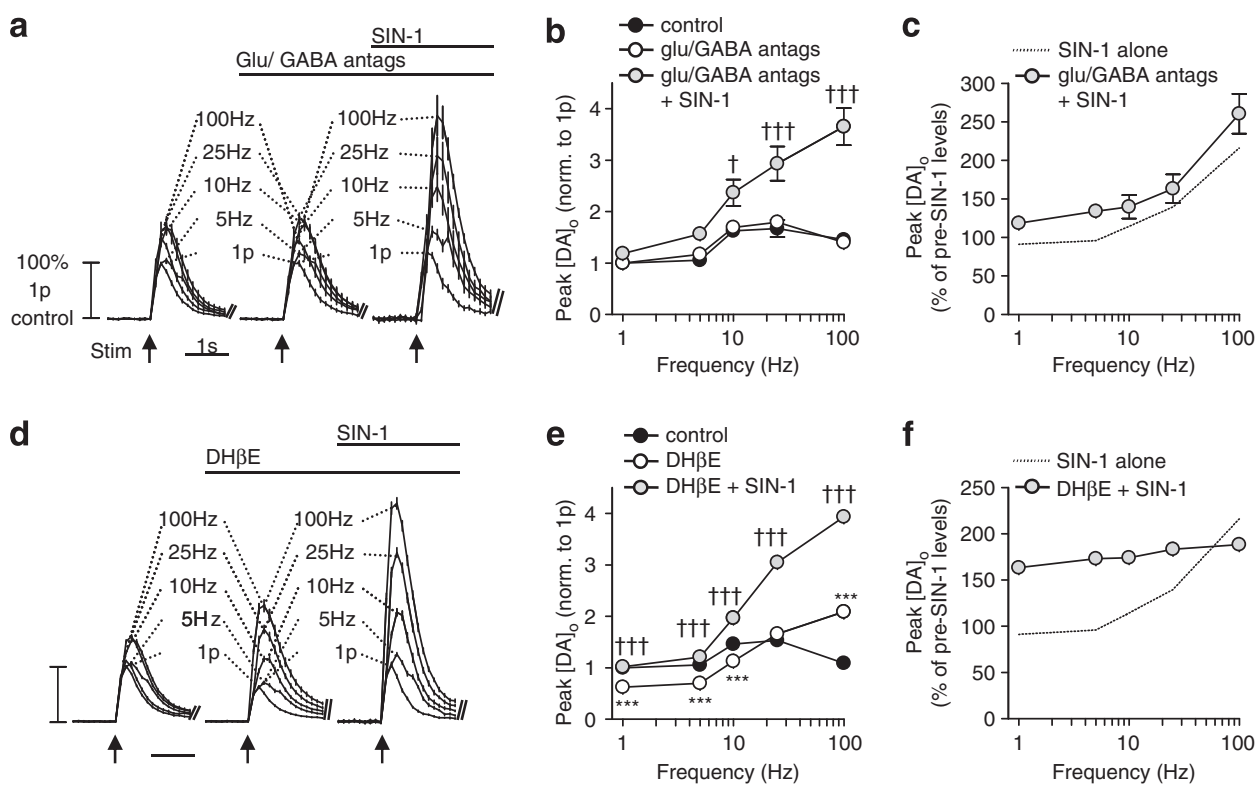

Figure 3 The effect of nitric oxide (NO) on dopamine (DA) release is independent of striatal glutamate or $\gamma$-aminobutyric acid (GABA) input, but varies with cholinergic input. (a, d) Profiles of mean extracellular DA concentration ([DA $\left.]_{0}\right) \pm$ standard error of mean (SEM) vs time following stimuli (arrows) of either one pulse (Ip) or four pulses $(4 \mathrm{p})(5-100 \mathrm{~Hz})$ in control conditions (left), antagonists (center) (a, glu/GABA antagonist cocktail (I0 $\mu$ M bicuculline, $50 \mu \mathrm{M}$ saclofen, $50 \mu \mathrm{M}$ D-AP5, $10 \mu \mathrm{M}$ GYKI-52466, $200 \mu \mathrm{M}$ (S)-MCPG); d, DH $\beta$ E, I $\mu \mathrm{M}$ ), and antagonists + 3-morpholinosydnonimine hydrochloride (SINI) $(500 \mu \mathrm{M})$ (right) normalized to peak [DA]。 evoked by Ip in controls. (b, e) Mean peak [DA]。 \pm SEM vs frequency during Ip or $4 p(5-100 \mathrm{~Hz})$ in control conditions (filled circles), antagonists (unfilled) (b, glu/GABA antagonists, $n=9-16$; e, DH $\beta \mathrm{E}, n=9-16$ ) and antagonists + SIN-I (gray fill) normalized to peak $[D A]_{\text {。 }}$ evoked by I $\mathrm{p}$ in controls. Asterisks indicate significance level in post hoc Bonferroni $t$-test vs controls, $* * * * P<0.00$ I. Crucifixes indicate significance level in Bonferroni post hoc $t$-tests for antagonist vs antagonist $+\mathrm{SIN}-\mathrm{I},{ }^{\dagger} P<0.05,{ }^{\dagger \dagger \dagger} P<0.00 \mathrm{I}$. (c, f) Mean peak [DA]。 vs frequency expressed as \% of peak [DA]。 evoked at that frequency before SIN-I cocktail application, to compare the effect of SIN-I on [DA]。 at each applied frequency in the presence of (c) Glu/ GABA antagonists or $(f), D H \beta E$, vs SIN-I alone (dashed line; determined from data in Figure Ib). Error bars are also the percentage of pre-SIN-I levels. 


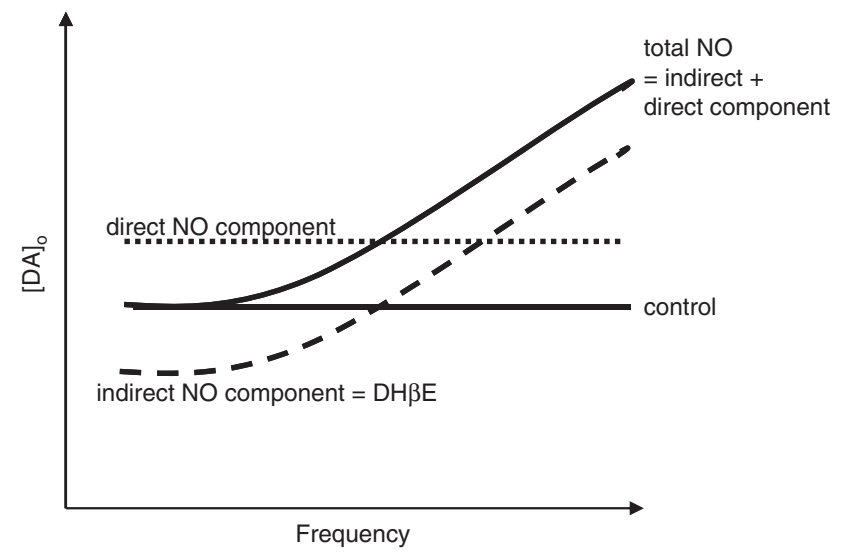

Figure 4 Direct and indirect effects of nitric oxide (NO) on dopamine (DA) release supplement each other at high-frequency DA neuron activity, but cancel out at low frequency. Cartoon to explain net outcome of the 'direct' and 'indirect' effects of NO on DA release evoked by varying frequencies of stimulation. 'Indirect' modulation of DA release by NO involving a net reduction of nicotinic ACh receptors ( $\mathrm{AAChR}$ ) control of DA would be expected to reduce DA release at low frequencies, but consequently enhance frequency sensitivity and then even enhance DA release at high frequencies (see, Cragg, 2006; Rice and Cragg, 2004). 'Direct' modulation of DA release by NO (seen in the absence of nAChR activation) increases DA concentration ([DA $]_{0}$ ) uniformly regardless of stimulus frequency. When $n A C h R$ tone is intact, these two mechanisms acting in concert will enhance [DA]。 at high frequencies, but cancel out at low frequencies.

to be set against an indirect action via the cholinergic system, with a net outcome to increase the sensitivity of DA release to frequency (Figure 4).

\section{DISCUSSION}

This study reveals that exogenous NO can powerfully and variably modulate DA release in the NAc core and enhance the frequency dependence of DA release. These NO-mediated effects are independent of sGC activation, and largely independent of two other candidate NO targets, DATs and BK channels. Furthermore, this frequencydependent modulation of DA release by NO appears to be multifactorial, involving an indirect action via (or interaction with) ACh released from ChIs, as well as a direct action on DA axons. These data reveal a variable neuromodulatory influence of local NO on DA in the NAc that depends on the activity in DA neurons as well as local accumbal circuits. Given the central role of DA neurotransmission in the NAc on motivated behaviors, interactions between NO, ACh and DA may be important for regulating these behaviors in normal as well as pathological states.

\section{NO Increases the Contrast of DA Signals Released by Phasic $v s$ Tonic Frequencies of Activity via GC-Independent Mechanism(s)}

Two separate NO donors, SIN-1 and PAPA/NONOate, increased evoked [DA $]_{\mathrm{o}}$ and enhanced the frequency sensitivity of DA release. Thus, NO donors enhanced the contrast between $[\mathrm{DA}]_{\mathrm{o}}$ evoked by phasic $v s$ tonic frequencies of activation. Donors were used at concentrations that are those typically used to produce effects of NO that are thought to be physiologically relevant (Bon and Garthwaite, 2001; East et al, 1991; Garthwaite et al, 2002; Luchowski and Urbanska, 2007; Yang and Cox, 2008). Here, the similar effects on DA release of these two different NO donors suggest that their outcomes are due to their common property to generate $\mathrm{NO}$ with physiological consequences rather than any nonspecific effects or other breakdown products of each compound.

The concentrations of NO that are physiological are still debated (Hall and Garthwaite, 2009). Current estimates of NO concentrations found during normal tissue functioning are in the range of hundreds of picomolar to low nanomolar (ie, $10^{-10}-10^{-8} \mathrm{M}$ ) (Hall and Garthwaite, 2009; Sammut et $a l, 2006)$ and are a function of the rates of NO production, diffusion, and consumption. Tissue concentrations of NO that result from the NO donors applied here will depend on the NO concentrations generated in solution (100- to 1000 -fold lower than the donor itself, for example, Feelisch et al (1989), Garthwaite et al (2002), and Hogg et al (1992)) and also on tissue penetration by NO. The high rate of consumption of NO by tissue is thought to result in a substantial concentration difference between NO applied in solution and the limited NO reaching tissue (estimated to be 1000 - to 10000 -fold lower in tissue; Hall and Garthwaite, 2006, 2009). Thus, taking these different 'dilution' factors into account in this study, the NO concentrations in tissue resulting from the donor concentrations applied in solution $\left(10^{-4} \mathrm{M}\right)$ may be between $10^{5}$ and $10^{7}$ times lower, that is, in the range of $10^{-9}-10^{-11} \mathrm{M}$. These picomolar to low nanomolar estimates are very similar to estimates of NO concentrations found physiologically. Indeed, the effects here were consistent with physiological and not pathological effects because they were completely reversible within minutes of washout. Furthermore, previous studies using isolated rat optic nerve preparations found no signs of nervous tissue damage after 2 -h exposure to $300 \mu \mathrm{M}$ PAPA/NONOate or a 4-h exposure to concentrations of SIN-1 (2 mM), an order of magnitude higher than those used here (Garthwaite et al, 2002). In addition, NO donor effects persisted in the presence of the peroxynitrite scavenger Trolox, indicating that they did not depend on a pathological conversion to peroxynitrite.

The enzyme sGC is an effector mechanism for some actions of NO. In the dorsal striatum, the sGC dependence of facilitatory effects of $\mathrm{NO}$ on DA levels remains debated and has been shown to be sGC-dependent in vivo (GuevaraGuzman et al, 1994; Trabace and Kendrick, 2000), but also sGC-independent both in vitro (Buyukuysal, 1997; Stewart et al, 1996) and in vivo (Rocchitta et al, 2004; West and Galloway, 1996). In our study in NAc, the effects of NO on dynamic DA signaling were not prevented by an inhibitor of sGC, indicating that they are sGC-independent. This is in line with previous in vitro studies in the dorsal striatum revealing sGC-independent effects of NO on DA release (Buyukuysal, 1997; Stewart et al, 1996).

Many target molecules have been identified in various systems to mediate the many physiological functions of NO. It has been suggested that NO might increase extracellular striatal DA levels via inhibition of DATs in some studies (Buyukuysal, 1997; Lonart and Johnson, 1994; Pogun et al, 1994). However, NO donors modified DA transmission in 
this study via a mechanism that did not involve any modulation of, or dependence on, DA uptake via DAT.

The conductance of $\mathrm{BK}$ channels (among other $\mathrm{K}^{+}$ channels) has also been reported to be modulated by NO, via both sGC-dependent and -independent mechanisms (Ahern et al, 1999; Klyachko et al, 2001). In posterior pituitary nerve terminals, NO has been reported to increase BK channel conductance, therefore promoting spike afterhyperpolarization and $\mathrm{Na}^{+}$-channel recovery from inactivation, and thus reducing action potential failures during spike trains (Klyachko et al, 2001). Such a mechanism would be expected to give rise to a short-term, frequencydependent enhancement of transmitter release, and was thus an attractive mechanism to explain NO effects on $[\mathrm{DA}]_{\mathrm{o}}$ described here. Although BK channel expression/ function has to date not been reported in DA neurons or axons, BK channels regulate neurotransmitter release from some other central neurons (eg, Xu et al, 2005) and are also present in the striatum, for example, in dorsal striatal ChIs where they contribute to action potential repolarization (Bennett et al, 2000). As striatal ACh potently regulates DA transmission in a manner that varies with presynaptic activity (Cragg, 2006; Rice and Cragg, 2004; Zhang and Sulzer, 2004), these channels on ChIs might in turn modulate DA release. However, although IbTx, a blocker of BK channels, slightly modified evoked [DA $]_{\mathrm{o}}$, it did not prevent significant frequency-dependent effects of SIN-1 on DA release in NAc. Taken together, these data suggest that the sGC-independent effector mechanisms involved in NO-mediated modulation of DA release do not require either the DAT or BK channels, and must involve an alternate target(s), of which there are numerous candidates, for example, $\mathrm{Na}^{+}$channels (Hammarstrom and Gage, 1999), the ryanodine receptor (Sun et al, 2001; Xu et al, 1998), L-type $\mathrm{Ca}^{2+}$ channel (Campbell et al, 1996; Summers et al, 1999), and cyclic nucleotide-gated channels (Broillet, 2000; Broillet and Firestein, 1996).

\section{NO Modulates DA Release via an Indirect ACh-Dependent Mechanism and via Direct Actions on Dopaminergic Terminals}

To identify which accumbal neuron type(s) mediate NO regulation of DA transmission, we explored whether these effects required local accumbal glutamatergic, GABAergic, or cholinergic inputs (eg, Bogdanov and Wurtman, 1997; Guevara-Guzman et al, 1994; Trabace and Kendrick, 2000; West and Galloway, 1997a). NO-mediated modulation of evoked DA release was independent of glutamate and GABA inputs, consistent with previous studies showing that neither glutamate nor GABA modulate DA release evoked by single pulses and brief $4-5$ pulse trains (Cragg, 2003; Exley et al, 2008; Threlfell et al, 2010).

NO has been shown to powerfully modulate the activity of ChIs in the dorsal striatum (Centonze et al, 2001) as well as the release of $\mathrm{ACh}$ in the dorsal and ventral striatum (Guevara-Guzman et al, 1994; Prast et al, 1995, 1998; Prast and Philippu, 2001; Trabace and Kendrick, 2000). Notably, $\mathrm{ACh}$ at nAChRs on DA axons has a major role in governing the frequency sensitivity of DA release (Exley et al, 2008; Rice and Cragg, 2004; Zhang and Sulzer, 2004). In this study, we reveal that when ACh action at nAChRs in NAc is prevented, the frequency-dependent effects of NO on DA transmission are also prevented. Without nAChR activity, NO then increases DA release independently of the frequency of activation. The simplest explanation for these data is that NO operates two partly opposing mechanisms that control DA release. One mechanism is indirect, involving regulation of $\mathrm{ACh}$ input to $\mathrm{nAChRs}$ akin to switching nAChRs off. Switching nAChRs off is expected to decrease DA release at low frequencies, but enhance frequency sensitivity of DA release, ultimately enabling enhanced DA release at high frequencies, and can result from either a decrease in ACh release or an increase sufficiently large to cause nAChR desensitization as seen with nicotine (Rice and Cragg, 2004; Zhang and Sulzer, 2004). The second mechanism, revealed in the absence of nAChR activation, appears to be directly located to DA axons, and increases evoked $[\mathrm{DA}]_{\mathrm{o}}$ uniformly regardless of stimulus frequency. When nAChR tone is intact, these two mechanisms acting in concert would be expected at low frequencies to oppose each other, resulting in no net effect. By contrast, at high frequencies, they would be expected to boost DA signals. These outcomes are indeed those observed here, and are summarized in a cartoon representation of individual and net effects (Figure 4).

Mechanistically, the increase in DA release by both direct and indirect actions of NO could be explained by an increase in vesicle fusion events as suggested for hippocampal synaptosomes by Meffert et al $(1996,1994)$. NO may increase the docking and fusion of dopaminergic vesicles at dopaminergic terminals, leading to an increase in release independent of frequency. In addition, NO may also increase the docking and fusion of cholinergic vesicles at cholinergic terminals, leading to an increase in ACh release that, as described above, could desensitize nAChRs with the effect of increasing DA release at high frequencies.

An action of NO at multiple neuronal sites with variable outcome would certainly be in keeping with the body of literature to date, indicating that NO that has diverse target molecules and proposed effector mechanisms and various reported outcomes on DA release (in the dorsal striatum). However, these data do not preclude an alternative explanation that NO regulation of DA transmission is via action at a single site, through a single mechanism that is in some way shunted at low frequencies in the presence of nAChR tone.

\section{Summary and Concluding Remarks}

Whether there are single or multiple effector mechanisms, these effects of NO donors, suggest that the action of endogenous $\mathrm{NO}$ on accumbal DA signaling may be highly dynamic, depending on DA axon activity and also on the state of the local ventral striatal network, especially ChIs. Our data suggest that during $\mathrm{ChI}$ and nAChR activation, accumbal NO might enhance how DA release conveys high frequencies of activation. This postulated action for NO would be in opposition to those of ACh, which limits the frequency dependence of DA signaling (Cragg, 2006). However, in the absence of $\mathrm{nAChR}$ activation by ACh, when the frequency dependence of DA signaling is great, NO might boost this outcome by promoting all DA signals uniformly. We speculate that $\mathrm{NO}$ might co-operate in 
outcome with the pauses in ChIs that signal motivationally significant stimuli (Aosaki et al, 1994; Apicella, 2002; Morris et al, 2004; Ravel et al, 2001; Shimo and Hikosaka, 2001), when $\mathrm{nAChR}$ activation will be minimal.

The neurons that are the most likely source of endogenous accumbal NO are nNOS-expressing, GABAergic interneurons that also contain somatostatin and neuropeptide Y (Beal et al, 1986; French et al, 2005; Smith and Parent, 1986) and are highly interconnected to form a local nNOScontaining interneuron network (French et al, 2005). Knowledge of their functions within the accumbal network is limited, but our data suggest that they might have a role in promoting transmission by DA of phasic $v s$ tonic activity in DA neurons. The outcome of endogenous NO on accumbal DA function might vary dynamically with activity within the accumbal neuron network and might also impact significantly on the behavioral outcome of activation of limbic basal ganglia loops.

\section{ACKNOWLEDGEMENTS}

The research was supported by a BBSRC DPhil studentship, a Foundation of German Business DPhil studentship (HH), The Wellcome Trust (Award to Dr SJ French), and Parkinson's UK (Grant No. 4067).

\section{DISCLOSURE}

The author(s) declare that, except for income received from my primary employer, no financial support or compensation has been received from any individual or corporate entity over the past 3 years for research or professional service and that there are no personal financial holdings that could be perceived as constituting a potential conflict of interest.

\section{REFERENCES}

Ahern GP, Hsu SF, Jackson MB (1999). Direct actions of nitric oxide on rat neurohypophysical $\mathrm{K}^{+}$channels. J Physiol 520(Part 1): 165-176.

Ahern GP, Klyachko VA, Jackson MB (2002). cGMP and S-nitrosylation: two routes for modulation of neuronal excitability by NO. Trends Neurosci 25: 510-517.

Aosaki T, Tsubokawa H, Ishida A, Watanabe K, Graybiel AM, Kimura M (1994). Responses of tonically active neurons in the primate's striatum undergo systematic changes during behavioral sensorimotor conditioning. J Neurosci 14: 3969-3984.

Apicella P (2002). Tonically active neurons in the primate striatum and their role in the processing of information about motivationally relevant events. Eur J Neurosci 16: 2017-2026.

Bayer HM, Glimcher PW (2005). Midbrain dopamine neurons encode a quantitative reward prediction error signal. Neuron 47: 129-141.

Beal MF, Chattha GK, Martin JB (1986). A comparison of regional somatostatin and neuropeptide $\mathrm{Y}$ distribution in rat striatum and brain. Brain Res 377: 240-245.

Bellamy TC, Wood J, Garthwaite J (2002). On the activation of soluble guanylyl cyclase by nitric oxide. Proc Natl Acad Sci USA 99: $507-510$.

Bennett BD, Callaway JC, Wilson CJ (2000). Intrinsic membrane properties underlying spontaneous tonic firing in neostriatal cholinergic interneurons. J Neurosci 20: 8493-8503.
Bennett BD, Wilson CJ (1999). Spontaneous activity of neostriatal cholinergic interneurons in vitro. J Neurosci 19: 5586-5596.

Berendse HW, Groenewegen HJ (1990). Organization of the thalamostriatal projections in the rat, with special emphasis on the ventral striatum. J Comp Neurol 299: 187-228.

Black MD, Matthews EK, Humphrey PP (1994). The effects of a photosensitive nitric oxide donor on basal and electricallystimulated dopamine efflux from the rat striatum in vitro. Neuropharmacology 33: 1357-1365.

Bogdanov MB, Wurtman RJ (1997). Possible involvement of nitric oxide in NMDA-induced glutamate release in the rat striatum: an in vivo microdialysis study. Neurosci Lett 221: 197-201.

Bon CL, Garthwaite J (2001). Nitric oxide-induced potentiation of CA1 hippocampal synaptic transmission during baseline stimulation is strictly frequency-dependent. Neuropharmacology 40: 501-507.

Broillet MC (2000). A single intracellular cysteine residue is responsible for the activation of the olfactory cyclic nucleotidegated channel by NO. J Biol Chem 275: 15135-15141.

Broillet MC, Firestein S (1996). Direct activation of the olfactory cyclic nucleotide-gated channel through modification of sulfhydryl groups by NO compounds. Neuron 16: 377-385.

Buyukuysal RL (1997). Effect of nitric oxide donors on endogenous dopamine release from rat striatal slices. II: The role of voltagedependent sodium channels, calcium channel activation, reverse transport mechanism, guanylate cyclase and endogenous glutamate. Fundam Clin Pharmacol 11: 528-536.

Calabresi P, Centonze D, Gubellini P, Marfia GA, Bernardi G (1999a). Glutamate-triggered events inducing corticostriatal long-term depression. J Neurosci 19: 6102-6110.

Calabresi P, Gubellini P, Centonze D, Sancesario G, Morello M, Giorgi M et al (1999b). A critical role of the nitric oxide/cGMP pathway in corticostriatal long-term depression. J Neurosci 19: 2489-2499.

Campbell DL, Stamler JS, Strauss HC (1996). Redox modulation of L-type calcium channels in ferret ventricular myocytes. Dual mechanism regulation by nitric oxide and S-nitrosothiols. J Gen Physiol 108: 277-293.

Centonze D, Pisani A, Bonsi P, Giacomini P, Bernardi G, Calabresi $P$ (2001). Stimulation of nitric oxide-cGMP pathway excites striatal cholinergic interneurons via protein kinase $\mathrm{G}$ activation. J Neurosci 21: 1393-1400.

Cragg SJ (2003). Variable dopamine release probability and shortterm plasticity between functional domains of the primate striatum. J Neurosci 23: 4378-4385.

Cragg SJ (2006). Meaningful silences: how dopamine listens to the ACh pause. Trends Neurosci 29: 125-131.

David HN, Ansseau M, Abraini JH (2005). Dopamine-glutamate reciprocal modulation of release and motor responses in the rat caudate-putamen and nucleus accumbens of 'intact' animals. Brain Res Brain Res Rev 50: 336-360.

East SJ, Batchelor AM, Garthwaite J (1991). Selective blockade of $\mathrm{N}$-methyl-D-aspartate receptor function by the nitric oxide donor, nitroprusside. Eur J Pharmacol 209: 119-121.

Edwards TM, Rickard NS (2005). A scavenger of peroxynitrite prevents long-term memory formation using a single trial passive avoidance task for the day-old chick. Neurobiol Learn Mem 83: 163-167.

Exley R, Clements MA, Hartung H, McIntosh JM, Cragg SJ (2008). Alpha6-containing nicotinic acetylcholine receptors dominate the nicotine control of dopamine neurotransmission in nucleus accumbens. Neuropsychopharmacology 33: 2158-2166.

Feelisch M, Noack EA (1987). Correlation between nitric oxide formation during degradation of organic nitrates and activation of guanylate cyclase. Eur J Pharmacol 139: 19.

Feelisch M, Ostrowski J, Noack E (1989). On the mechanism of NO release from sydnonimines. J Cardiovasc Pharmacol 14(Suppl 11): S13-S22. 
Finch DM (1996). Neurophysiology of converging synaptic inputs from the rat prefrontal cortex, amygdala, midline thalamus, and hippocampal formation onto single neurons of the caudate/ putamen and nucleus accumbens. Hippocampus 6: 495-512.

French SJ, Ritson GP, Hidaka S, Totterdell S (2005). Nucleus accumbens nitric oxide immunoreactive interneurons receive nitric oxide and ventral subicular afferents in rats. Neuroscience 135: 121.

French SJ, Totterdell S (2002). Hippocampal and prefrontal cortical inputs monosynaptically converge with individual projection neurons of the nucleus accumbens. J Comp Neurol 446: 151-165.

French SJ, Totterdell S (2003). Individual nucleus accumbensprojection neurons receive both basolateral amygdala and ventral subicular afferents in rats. Neuroscience 119: 19-31.

Garthwaite G, Goodwin DA, Batchelor AM, Leeming K, Garthwaite $\mathrm{J}$ (2002). Nitric oxide toxicity in CNS white matter: an in vitro study using rat optic nerve. Neuroscience 109: 145-155.

Garthwaite J, Boulton CL (1995). Nitric oxide signaling in the central nervous system. Annu Rev Physiol 57: 683-706.

Groenewegen HJ, Trimble M (2007). The ventral striatum as an interface between the limbic and motor systems. CNS Spectr 12: 887-892.

Groenewegen HJ, Vermeulen-Van der Zee E, te Kortschot A, Witter MP (1987). Organization of the projections from the subiculum to the ventral striatum in the rat. A study using anterograde transport of Phaseolus vulgaris leucoagglutinin. Neuroscience 23: 103-120.

Groenewegen HJ, Wright CI, Beijer AV (1996). The nucleus accumbens: gateway for limbic structures to reach the motor system? Prog Brain Res 107: 485-511.

Groenewegen HJ, Wright CI, Beijer AV, Voorn P (1999). Convergence and segregation of ventral striatal inputs and outputs. Ann N Y Acad Sci 877: 49-63.

Guevara-Guzman R, Emson PC, Kendrick KM (1994). Modulation of in vivo striatal transmitter release by nitric oxide and cyclic GMP. J Neurochem 62: 807-810.

Hall CN, Garthwaite J (2006). Inactivation of nitric oxide by rat cerebellar slices. J Physiol 577(Part 2): 549-567.

Hall CN, Garthwaite J (2009). What is the real physiological NO concentration in vivo? Nitric Oxide 21: 92-103.

Halliwell B, Evans P, Whiteman M (1999). Assessment of peroxynitrite scavengers in vitro. Methods Enzymol 301: 333-342.

Hammarstrom AK, Gage PW (1999). Nitric oxide increases persistent sodium current in rat hippocampal neurons. J Physiol 520(Part 2): 451-461.

Hidaka S, Totterdell S (2001). Ultrastructural features of the nitric oxide synthase-containing interneurons in the nucleus accumbens and their relationship with tyrosine hydroxylase-containing terminals. J Comp Neurol 431: 139-154.

Hogg N, Darley-Usmar VM, Wilson MT, Moncada S (1992). Production of hydroxyl radicals from the simultaneous generation of superoxide and nitric oxide. Biochem J 281(Part 2): 419-424.

Hyland BI, Reynolds JN, Hay J, Perk CG, Miller R (2002). Firing modes of midbrain dopamine cells in the freely moving rat. Neuroscience 114: 475-492.

Ikemoto S (2007). Dopamine reward circuitry: two projection systems from the ventral midbrain to the nucleus accumbensolfactory tubercle complex. Brain Res Rev 56: 27-78.

Iravani MM, Millar J, Kruk ZL (1998). Differential release of dopamine by nitric oxide in subregions of rat caudate putamen slices. J Neurochem 71: 1969-1977.

Jones SR, Garris PA, Kilts CD, Wightman RM (1995a). Comparison of dopamine uptake in the basolateral amygdaloid nucleus, caudate-putamen, and nucleus accumbens of the rat. $J$ Neurochem 64: 2581-2589.

Jones SR, Garris PA, Wightman RM (1995b). Different effects of cocaine and nomifensine on dopamine uptake in the caudate- putamen and nucleus accumbens. J Pharmacol Exp Ther 274: 396-403.

Jones SR, O’Dell SJ, Marshall JF, Wightman RM (1996). Functional and anatomical evidence for different dopamine dynamics in the core and shell of the nucleus accumbens in slices of rat brain. Synapse 23: 224-231.

Kiss JP, Hennings EC, Zsilla G, Vizi ES (1999). A possible role of nitric oxide in the regulation of dopamine transporter function in the striatum. Neurochem Int 34: 345-350.

Kiss JP, Vizi ES (2001). Nitric oxide: a novel link between synaptic and nonsynaptic transmission. Trends Neurosci 24: 211.

Klyachko VA, Ahern GP, Jackson MB (2001). cGMP-mediated facilitation in nerve terminals by enhancement of the spike afterhyperpolarization. Neuron 31: 1015-1025.

Kraus MM, Prast H (2001). The nitric oxide system modulates the in vivo release of acetylcholine in the nucleus accumbens induced by stimulation of the hippocampal fornix/fimbriaprojection. Eur J Neurosci 14: 1105-1112.

Liang LP, Kaufman S (1998). The regulation of dopamine release from striatum slices by tetrahydrobiopterin and L-argininederived nitric oxide. Brain Res 800: 181-186.

Lin AM, Kao LS, Chai CY (1995). Involvement of nitric oxide in dopaminergic transmission in rat striatum: an in vivo electrochemical study. J Neurochem 65: 2043-2049.

Lonart G, Cassels KL, Johnson KM (1993). Nitric oxide induces calcium-dependent $\left[{ }^{3} \mathrm{H}\right]$ dopamine release from striatal slices. J Neurosci Res 35: 192-198.

Lonart G, Johnson KM (1994). Inhibitory effects of nitric oxide on the uptake of $\left[{ }^{3} \mathrm{H}\right]$ dopamine and $\left[{ }^{3} \mathrm{H}\right]$ glutamate by striatal synaptosomes. J Neurochem 63: 2108-2117.

Luchowski P, Urbanska EM (2007). SNAP and SIN-1 increase brain production of kynurenic acid. Eur J Pharmacol 563: 130-133.

Matsumoto M, Hikosaka O (2009). Two types of dopamine neuron distinctly convey positive and negative motivational signals. Nature 459: 837-841.

Meffert MK, Calakos NC, Scheller RH, Schulman H (1996). Nitric oxide modulates synaptic vesicle docking fusion reactions. Neuron 16: 1229-1236.

Meffert MK, Premack BA, Schulman H (1994). Nitric oxide stimulates $\mathrm{Ca}(2+)$-independent synaptic vesicle release. Neuron 12: $1235-1244$.

Mogenson GJ, Jones DL, Yim CY (1980). From motivation to action: functional interface between the limbic system and the motor system. Prog Neurobiol 14: 69-97.

Morris G, Arkadir D, Nevet A, Vaadia E, Bergman H (2004). Coincident but distinct messages of midbrain dopamine and striatal tonically active neurons. Neuron 43: 133-143.

Morris G, Schmidt R, Bergman H (2010). Striatal action-learning based on dopamine concentration. Exp Brain Res 200: 307-317.

Mulder AB, Hodenpijl MG, Lopes da Silva FH (1998). Electrophysiology of the hippocampal and amygdaloid projections to the nucleus accumbens of the rat: convergence, segregation, and interaction of inputs. J Neurosci 18: 5095-5102.

O'Donnell P, Greene J, Pabello N, Lewis BL, Grace AA (1999). Modulation of cell firing in the nucleus accumbens. Ann NY Acad Sci 877: 157-175.

Pogun S, Baumann MH, Kuhar MJ (1994). Nitric oxide inhibits $\left[{ }^{3} \mathrm{H}\right]$ dopamine uptake. Brain Res 641: 83-91.

Prast H, Fischer H, Werner E, Werner-Felmayer G, Philippu A (1995). Nitric oxide modulates the release of acetylcholine in the ventral striatum of the freely moving rat. Naunyn Schmiedebergs Arch Pharmacol 352: 67-73.

Prast H, Philippu A (2001). Nitric oxide as modulator of neuronal function. Prog Neurobiol 64: 51-68.

Prast H, Tran MH, Fischer H, Philippu A (1998). Nitric oxideinduced release of acetylcholine in the nucleus accumbens: role of cyclic GMP, glutamate, and GABA. J Neurochem 71: 266-273. 
Ravel S, Sardo P, Legallet E, Apicella P (2001). Reward unpredictability inside and outside of a task context as a determinant of the responses of tonically active neurons in the monkey striatum. J Neurosci 21: 5730-5739.

Regoli F, Winston GW (1999). Quantification of total oxidant scavenging capacity of antioxidants for peroxynitrite, peroxyl radicals, and hydroxyl radicals. Toxicol Appl Pharmacol 156: 96-105.

Reynolds JN, Wickens JR (2002). Dopamine-dependent plasticity of corticostriatal synapses. Neural Netw 15: 507-521.

Rice ME, Cragg SJ (2004). Nicotine amplifies reward-related dopamine signals in striatum. Nat Neurosci 7: 583-584.

Rocchitta G, Migheli R, Mura MP, Esposito G, Desole MS, Miele E et al (2004). Signalling pathways in the nitric oxide donorinduced dopamine release in the striatum of freely moving rats: evidence that exogenous nitric oxide promotes $\mathrm{Ca}^{2+}$ entry through store-operated channels. Brain Res 1023: 243-252.

Sammut S, Dec A, Mitchell D, Linardakis J, Ortiguela M, West AR (2006). Phasic dopaminergic transmission increases NO efflux in the rat dorsal striatum via a neuronal NOS and a dopamine $\mathrm{D}(1 / 5)$ receptor-dependent mechanism. Neuropsychopharmaco$\log y$ 31: 493-505.

Schmitz Y, Schmauss C, Sulzer D (2002). Altered dopamine release and uptake kinetics in mice lacking D2 receptors. J Neurosci 22: 8002-8009.

Schultz W (1986). Responses of midbrain dopamine neurons to behavioral trigger stimuli in the monkey. J Neurophysiol 56: 1439-1461.

Schultz W (2002). Getting formal with dopamine and reward. Neuron 36: 241-263.

Schultz W (2010). Dopamine signals for reward value and risk: basic and recent data. Behav Brain Funct 6: 24.

Segovia G, Mora F (1998). Role of nitric oxide in modulating the release of dopamine, glutamate, and GABA in striatum of the freely moving rat. Brain Res Bull 45: 275-279.

Sesack SR, Grace AA (2010). Cortico-basal ganglia reward network: microcircuitry. Neuropsychopharmacology 35: 27-47.

Shimo Y, Hikosaka O (2001). Role of tonically active neurons in primate caudate in reward-oriented saccadic eye movement. $J$ Neurosci 21: 7804-7814.

Silva MT, Rose S, Hindmarsh JG, Aislaitner G, Gorrod JW, Moore $\mathrm{PK}$ et al (1995). Increased striatal dopamine efflux in vivo following inhibition of cerebral nitric oxide synthase by the novel monosodium salt of 7-nitro indazole. Br J Pharmacol 114: 257-258.

Silva MT, Rose S, Hindmarsh JG, Jenner P (2003). Inhibition of neuronal nitric oxide synthase increases dopamine efflux from rat striatum. J Neural Transm 110: 353-362.

Smith Y, Parent A (1986). Neuropeptide Y-immunoreactive neurons in the striatum of cat and monkey: morphological characteristics, intrinsic organization and co-localization with somatostatin. Brain Res 372: 241-252.

Smith Y, Raju DV, Pare JF, Sidibe M (2004). The thalamostriatal system: a highly specific network of the basal ganglia circuitry. Trends Neurosci 27: 520-527.

Stewart TL, Michel AD, Black MD, Humphrey PP (1996). Evidence that nitric oxide causes calcium-independent release of $\left[{ }^{3} \mathrm{H}\right]$ dopamine from rat striatum in vitro. J Neurochem 66: 131-137.

Summers BA, Overholt JL, Prabhakar NR (1999). Nitric oxide inhibits L-type $\mathrm{Ca}^{2+}$ current in glomus cells of the rabbit carotid body via a cGMP-independent mechanism. J Neurophysiol 81: 1449-1457.
Sun J, Xin C, Eu JP, Stamler JS, Meissner G (2001). Cysteine-3635 is responsible for skeletal muscle ryanodine receptor modulation by NO. Proc Natl Acad Sci USA 98: 11158-11162.

Threlfell S, Clements MA, Khodai T, Pienaar IS, Exley R, Wess J et al (2010). Striatal muscarinic receptors promote activity dependence of dopamine transmission via distinct receptor subtypes on cholinergic interneurons in ventral $v s$ dorsal striatum. J Neurosci 30: 3398-3408.

Trabace L, Kendrick KM (2000). Nitric oxide can differentially modulate striatal neurotransmitter concentrations via soluble guanylate cyclase and peroxynitrite formation. J Neurochem 75: 1664-1674.

Voorn P, Jorritsma-Byham B, Van Dijk C, Buijs RM (1986). The dopaminergic innervation of the ventral striatum in the rat: a light- and electron-microscopical study with antibodies against dopamine. J Comp Neurol 251: 84-99.

West AR, Galloway MP (1996). Intrastriatal infusion of (+/-)-Snitroso- $N$-acetylpenicillamine releases vesicular dopamine via an ionotropic glutamate receptor-mediated mechanism: an in vivo microdialysis study in chloral hydrate-anesthetized rats. J Neurochem 66: 1971-1980.

West AR, Galloway MP (1997a). Endogenous nitric oxide facilitates striatal dopamine and glutamate efflux in vivo: role of ionotropic glutamate receptor-dependent mechanisms. Neuropharmacology 36: $1571-1581$.

West AR, Galloway MP (1997b). Inhibition of glutamate reuptake potentiates endogenous nitric oxide-facilitated dopamine efflux in the rat striatum: an in vivo microdialysis study. Neurosci Lett 230: $21-24$

West AR, Galloway MP (1998). Nitric oxide and potassium chloridefacilitated striatal dopamine efflux in vivo: role of calciumdependent release mechanisms. Neurochem Int 33: 493-501.

West AR, Grace AA (2000). Striatal nitric oxide signaling regulates the neuronal activity of midbrain dopamine neurons in vivo. $J$ Neurophysiol 83: 1796-1808.

West AR, Grace AA (2004). The nitric oxide-guanylyl cyclase signaling pathway modulates membrane activity states and electrophysiological properties of striatal medium spiny neurons recorded in vivo. J Neurosci 24: 1924-1935.

Wright CI, Groenewegen HJ (1995). Patterns of convergence and segregation in the medial nucleus accumbens of the rat: relationships of prefrontal cortical, midline thalamic, and basal amygdaloid afferents. J Comp Neurol 361: 383-403.

Xu JW, Hou M, Slaughter MM (2005). Photoreceptor encoding of supersaturating light stimuli in salamander retina. J Physiol 569(Part 2): 575-585.

$\mathrm{Xu}$ L, Eu JP, Meissner G, Stamler JS (1998). Activation of the cardiac calcium release channel (ryanodine receptor) by poly-Snitrosylation. Science 279: 234-237.

Yang S, Cox CL (2008). Excitatory and anti-oscillatory actions of nitric oxide in thalamus. $J$ Physiol 586(Part 15): 3617-3628.

Zahm DS (2000). An integrative neuroanatomical perspective on some subcortical substrates of adaptive responding with emphasis on the nucleus accumbens. Neurosci Biobehav Rev 24: 85-105.

Zhang H, Sulzer D (2004). Frequency-dependent modulation of dopamine release by nicotine. Nat Neurosci 7: 581-582.

Zhou FM, Liang Y, Dani JA (2001). Endogenous nicotinic cholinergic activity regulates dopamine release in the striatum. Nat Neurosci 4: 1224-1229.

Zhu XZ, Luo LG (1992). Effect of nitroprusside (nitric oxide) on endogenous dopamine release from rat striatal slices. J Neurochem 59: 932-935.

Supplementary Information accompanies the paper on the Neuropsychopharmacology website (http://www.nature.com/npp) 